\title{
Perioperative Respiratory Adverse Events Among Pediatric Surgical Patients in University Hospitals in Northwest Ethiopia; A Prospective Observational Study
}

\author{
Desalegn Muche Wudineh ${ }^{1}$, Yophtahe Woldegerima Berhe ${ }^{2 *}$, Wubie Birlie Chekol ${ }^{2}$, \\ Habtu Adane $^{2}$ and Misganaw Mengie Workie ${ }^{2}$ \\ ${ }^{1}$ Felege-Hiwot Referral Hospital, Bahirdar, Ethiopia, ${ }^{2}$ Department of Anesthesia, University of Gondar, Gondar, Ethiopia
}

OPEN ACCESS

Edited by:

Anju Gupta,

All India Institute of Medical

Sciences, India

Reviewed by:

Raghav Gupta,

All India Institute of Medical

Sciences, India

Aleksandr Urakov,

Izhevsk State Medical

Academy, Russia

*Correspondence:

Yophtahe Woldegerima Berhe

yophti@gmail.com

orcid.org/0000-0002-0988-7723

Specialty section:

This article was submitted to Pediatric Critical Care,

a section of the journal

Frontiers in Pediatrics

Received: 08 December 2021

Accepted: 10 January 2022

Published: 11 February 2022

Citation:

Wudineh DM, Berhe YW, Chekol WB Adane $\mathrm{H}$ and Workie MM (2022)

Perioperative Respiratory Adverse Events Among Pediatric Surgical Patients in University Hospitals in Northwest Ethiopia; A Prospective Observational Study.

Front. Pediatr. 10:827663. doi: 10.3389/fped.2022.827663
Introduction: Perioperative respiratory adverse events (PRAEs) are frequent among pediatrics surgical patients and are accountable for $3 / 4^{\text {th }}$ of perioperative critical incidents and $1 / 3^{\text {rd }}$ of cardiac arrests.

Objective: Assess the prevalence and factors associated with PRAEs among pediatric surgical patients in University Hospitals in Northwest Ethiopia, 2020.

Methodology: After ethical approval obtained prospective observational study was conducted among 210 pediatric surgical patients. Perioperative respiratory adverse events were defined as the occurrence of any episode of single/combination of coughing, breath holding, hypoxemia, laryngospasm and bronchospasm. Bivariate and multivariate binary logistic regression analyses were performed and variables with $p<0.05$ at 95\% confidence interval were considered as statistically significant.

Results: The prevalence of PRAEs was 26.2\% (Cl: 20.5-30.9\%). A total of 129 episodes of PRAEs were occurred and of them, 89 (69.0\%) were occurred in the postoperative period. Desaturation was the predominant adverse event which was observed 61 (47.3\%) times. Age < 1 year (AOR: 3.6, Cl: 1.3-10.0), ASA $\geq 3$ (AOR: 5.2, Cl: 1.9-22.9), upper respiratory tract infections (URTIs) (AOR: 7.6, Cl: 1.9-30.2), secretions in the upper airway (AOR: 4.8, Cl: 1.4-15.9) and airway related surgery (AOR: 6.0, Cl: 1.5-24.1) were significantly associated with PRAEs.

Conclusions: Prevalence of PRAEs was high among pediatric surgical patients; the postoperative period was the most critical time for the occurrence of PRAEs and desaturation was the commonest PRAE. Age $<1$ year, URTIs (recent or active), secretions in the upper airways, ASA $\geq 3$ and airway related surgery were significantly associated with PRAEs. Clinicians should perform effective risk assessment, preoperative optimization and preparation for the management of PRAEs.

Keywords: perioperative respiratory adverse events, perioperative complications, pediatric anesthesia, general anesthesia, adverse events 


\section{INTRODUCTION}

Adverse event is defined as unanticipated and unwanted response to medical intervention during the perioperative period that can threaten patient wellbeing. Respiratory adverse events are any episodes of desaturation, partial or complete airway obstruction, persistent coughing, breath holding and bronchospasm (1-3). Despite improvements in pediatrics anesthesia, respiratory adverse events are still the most frequent cause of serious morbidity and mortality in the perioperative period. The $3 / 4^{\text {th }}$ of all critical incidents and the $1 / 3^{\text {rd }}$ of all perioperative cardiac arrests in pediatric anesthesia are caused by respiratory adverse events. Preoperative identification of those children at high risk is a challenging process (4, 5). Children are vulnerable to respiratory adverse events because of anatomical and physiological considerations and frequent respiratory tract infections (URTIs). The most common respiratory adverse events under anesthesia are desaturation, breath holding, laryngospasm, bronchospasm and coughing. Among these, laryngospasm, bronchospasm and persistent hypoxemia could result potentially devastating complication and death (6-8).

Inconsistent definitions of respiratory adverse events among studies make comparisons difficult and results in discrepancy on magnitude of the actual events (1). Despite introduction of new monitoring modalities, pharmacological products and new clinical practice guidelines, the prevalence of respiratory adverse events has remained high and increased length of hospital stay and medical costs $(1,9)$. The patient's age, techniques of anesthesia induction, comorbidities and airway surgery were strongly associated with increased occurrence of adverse events during surgery. Occurrence of respiratory adverse events differs according to timing of extubation whether awake or deep plane of anesthesia, airway device and urgency of procedures $(10,11)$. The severity of PRAEs and their complications depends on the nature of surgery, presence comorbidity, early detection, and prompt corrective measures. It may range from transient damage with full recovery to unanticipated morbidity and mortality (2). Risk assessment in the preoperative period is very important to decrease respiratory adverse events but still patient identification and selection are real challenges. If effective measures are not taken timely, serious complications and death would prevail. "Critical respiratory incident recording and reporting system is poor particularly in the developing countries due to multiple reasons" (12). The general objective of the current study was to assess the prevalence and factors associated with PRAEs among pediatrics surgical patients.

Abbreviations: AOR, Adjusted Odds Ratio; ASA, American Society of Anesthesiologist; COVID-19, Corona Virus Disease-2019; GA, General Anesthesia; LMA, Laryngeal Mask Airways; PRAEs, Perioperative Respiratory Adverse Events; SPO2, Peripheral Oxygen Saturation; SPSS, Statistical Package for Social Science; TGSH, Tibebe-Ghion Specialized Hospital; UoGCSH, University of Gondar Comprehensive and Specialized Hospital; URTIs, Upper Respiratory Tract Infections.

\section{METHODOLOGY}

A prospective observational study was conducted from March 1 to May 30, 2020 at the University of Gondar Comprehensive Specialized Hospital (UoGCSH) and Tibebe-Ghion Specialized Hospital (TGSH). The hospitals are located at Gondar and Bahirdar towns respectively in the Northwest Ethiopia. The source population was all pediatric surgical patients $(0-12$ years of age) that underwent surgery under general anesthesia and the study population was all pediatric surgical patients that underwent surgery under general anesthesia at UoGCSH and TGSH during the study period. All pediatric surgical patients whose parents/legal care-givers were volunteer were included and patients who had severe head injury, intubated patient, acute respiratory distress, hypoxia requiring mechanical ventilation in the preoperative period, operated for more than once, and transferred to intensive care unit for mechanical ventilation after operation were excluded.

Sample size was calculated by using single population proportion formula with $50 \%$ proportion, maximum acceptable difference $(\mathrm{d})=5 \%$, and $95 \%$ confidence interval and found 385. We used a reduction formula to determine achievable sample size as the surgical registries showed that only 780 and 660 pediatrics surgical procedures were performed annually at UGCSH and TGCSH respectively. In-addition, due to COVID19 pandemic, the flow of pediatric surgical patients was reduced. After reduction, the sample size became 195 and 15\% nonresponse rate was added and the final sample size was 225 .

All eligible pediatric surgical patients who received general anesthesia were included in the study. The dependent variables were PRAEs which were measured in terms of any episode of either coughing, breath holding, hypoxemia, laryngospasm, or bronchospasm. The independent variables were patient factors (history of prematurity, age, ASA classification, family history of asthma, URTIs, and other comorbidities), anesthetic factors (techniques of anesthetic induction, type of airway device, number of intubation attempts, muscle relaxant, depth of anesthesia, perioperative opioid use, and experience of the anesthesia providers), and surgical aspects (surgical site, duration, and urgency).

\section{Operational Definitions}

Perioperative respiratory adverse event: any episode of single/combination of coughing, breathe holding, hypoxemia, laryngospasm and bronchospasm (2, 3, 13-19). Detailed operational definitions were prepared accordingly.

Laryngospasm: complete airway obstruction with abdominal and chest muscle rigidity that require positive pressure ventilation or administration of succinylcholine (1).

Bronchospasm: increased work of breathing, particularly during expiration and wheezing on auscultation or requires bronchodilators $(7,13)$.

Desaturation or hypoxemia: peripheral arterial oxyhemoglobin saturation $\left(\mathrm{SpO}_{2}\right)<95 \%$ more than 30 seconds measured by pulse oximetry regardless administrations 
TABLE 1 | Perioperative respiratory adverse events severity scoring in pediatrics patients underwent surgery under general anesthesia.

\begin{tabular}{|c|c|c|c|c|}
\hline \multirow[t]{2}{*}{ Parameters } & \multicolumn{4}{|c|}{ Severity score } \\
\hline & $\begin{array}{l}1 \\
\text { (No adverse event) }\end{array}$ & 2 & 3 & $\begin{array}{l}4 \\
\text { (Serious adverse events) }\end{array}$ \\
\hline $\mathrm{SpO}_{2}$ & $95-100$ & $90-94$ & 80-89 & $<80$ \\
\hline Coughing (n) & None & $1-2$ & $3-4$ & Continuous \\
\hline $\begin{array}{l}\text { Breath holding } \\
\text { (seconds) }\end{array}$ & None & $<15$ & $15-30$ & $>30$ \\
\hline Laryngospasm & None & $\begin{array}{l}\text { Partial obstruction } \\
\text { requires repositioning } \\
\text { only }\end{array}$ & $\begin{array}{l}\text { Partial obstruction } \\
\text { requires CPAP }\end{array}$ & $\begin{array}{l}\text { Complete obstruction } \\
\text { requires muscle relaxant }\end{array}$ \\
\hline Bronchospasm & None & Expiration phase only & $\begin{array}{l}\text { Expiration and } \\
\text { inspiration phase }\end{array}$ & $\begin{array}{l}\text { Difficult to ventilate: } \\
\text { treatment needed }\end{array}$ \\
\hline Secretions & None & Minimal: no suctioning & $\begin{array}{l}\text { Moderate: one } \\
\text { suctioning }\end{array}$ & $\begin{array}{l}\text { Copious: more than one } \\
\text { suctioning }\end{array}$ \\
\hline
\end{tabular}

of $100 \%$ Oxygen or $\mathrm{SpO}_{2}<90 \%$ in atmospheric air. Oxygen saturation was documented when pulse oximetry showed consistent readings with no artifacts $(2,7)$.

Coughing: a series of pronounced, persistent coughs lasting more than $5 \mathrm{~s}$ (7).

Breath holding or apnea: if the patient had apnea more than $15 \mathrm{~s}$ or irregular breathing or if the apnea is associated with bradycardia or cyanosis (13).

Partial upper airway obstruction: airway obstruction in the combination with snoring, inspiratory stridor or increased breathing efforts or paradoxical abdominal movement or both that can be effectively relieved by simple airway maneuvers (2).

Multiple intubation attempts: if required multiple intubation attempts $\geq 3$ times (20). Active or current URTIs: the present of at least of two URTIs symptoms (rhinorrhea, sneezing, nasal congestion, sore or scratchy throat, cough, malaise, or fever $>$ $38^{\circ} \mathrm{C}$ ) at the time of surgery together with a confirmation by a parent (13).

Active/Recent URTIs: symptomatic URTIs during/within 2 weeks of the perioperative period was considered as active URTIs. If the URTIs occurred within 2-4 weeks before surgery but resolved at the time of surgery, it was considered as recent URTIs (13).

Acute respiratory distress: the presence of tachypnea, nasal flaring, grunting, intercostal and subcostal retractions, and cyanosis in room air and requires high flow Oxygen (21).

Light anesthesia: the presence of patient's movement with tachypnea, tachycardia and hypertension (change by more than $30 \%$ from baseline) (22).

Oropharyngeal secretions: the presence of secretion that requires suctioning of more than once (23).

Pulmonary aspiration: confirmed or suspected entrance of foreign materials such as gastric contents into the respiratory tract result in new/worsening respiratory signs such as hypoxia (24).

Airway related surgery: surgery that involve the airway which includes ENT and maxillofacial procedures such as adenotonsilectomy, cleft palate repair, direct laryngoscopy, and bronchoscopy $(23,25,26)$.
All complications were scored according to severity from 1 (no complication) to 4 (serious complication). For patients who received anesthesia with endotracheal tubes or laryngeal mask airways, scores were multiplied by a constant factor of five. When facemask was used, scores were multiplied by a constant factor of three. Patients received a composite score of 5-20 for ETT or LMA and 3-12 facemask for each adverse event (Table 1) (23). The PRAEs were recorded starting from induction to the first postoperative hour. A patient experiencing PRAEs was counted just once independent of the numbers of events in perioperative period.

Ethical approval (Reference No: PGC/587/07/2012) was obtained from the Ethical Review Committee of School of Medicine, University of Gondar. Written informed consent was obtained from parents/legal care-givers of each child. When clinically significant PRAEs were noticed, data collectors reported for clinicians (Anesthetist, Surgeon or Nurse) to provide appropriate management. A pre-test was conducted on 20 (8\%) patients whose data were not included in the main study. The data were analyzed by using SPSS version 20 (IBM Corporate). The normality was checked by using Shapiro-Wilk normality test. The Chi-squared or Fisher's exact tests were used when appropriate. The Hosmer-Lemeshow test was used to assess model fitness. The variance inflation factors and tolerance were used to diagnose multicollinearity. The associations between variables were determined by using bivariate and multivariate binary logistic regression. The cut-point of statistical significance was $p<0.2$ for bivariate and $<0.05$ for multivariate regression at $95 \%$ confidence interval. Odds Ratio were used to describe the strength of associations.

\section{RESULTS}

Two hundred ten (210) pediatric surgical patients who received general anesthesia were included in this study. The response rate was $93.3 \%$ and data from 15 patients were excluded due to incompleteness. The majority of the patients 115 (54.8\%) were males. The median age (inter-quartile range) was 4.0 (1.1-8.0) 
TABLE 2 | Clinical characteristics of pediatric surgical patients who underwent surgery under general anesthesia in UoGCSH and TGSH from March 1-May 30, 2020 (N $=210)$.

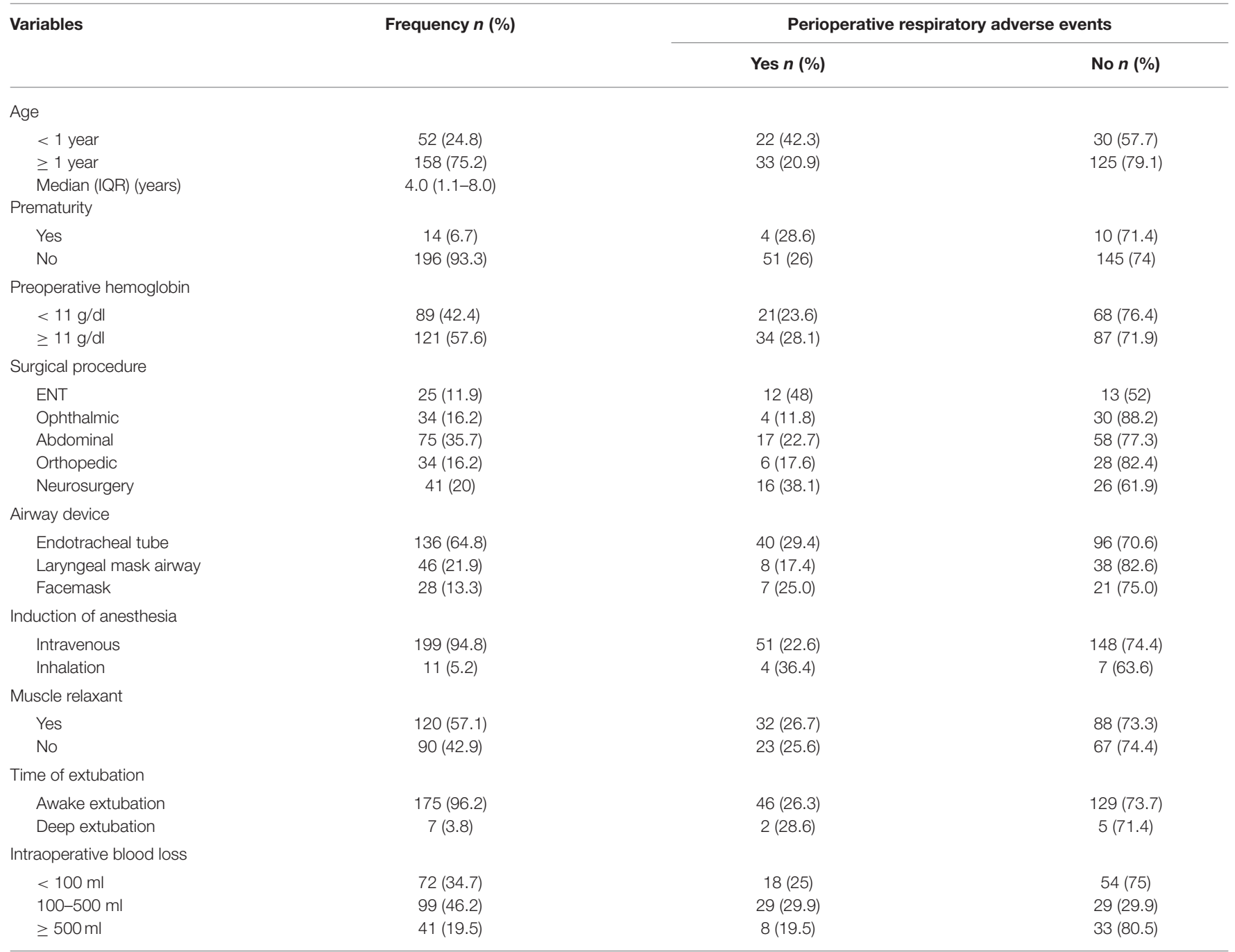

IQR, Inter-quartile Range.

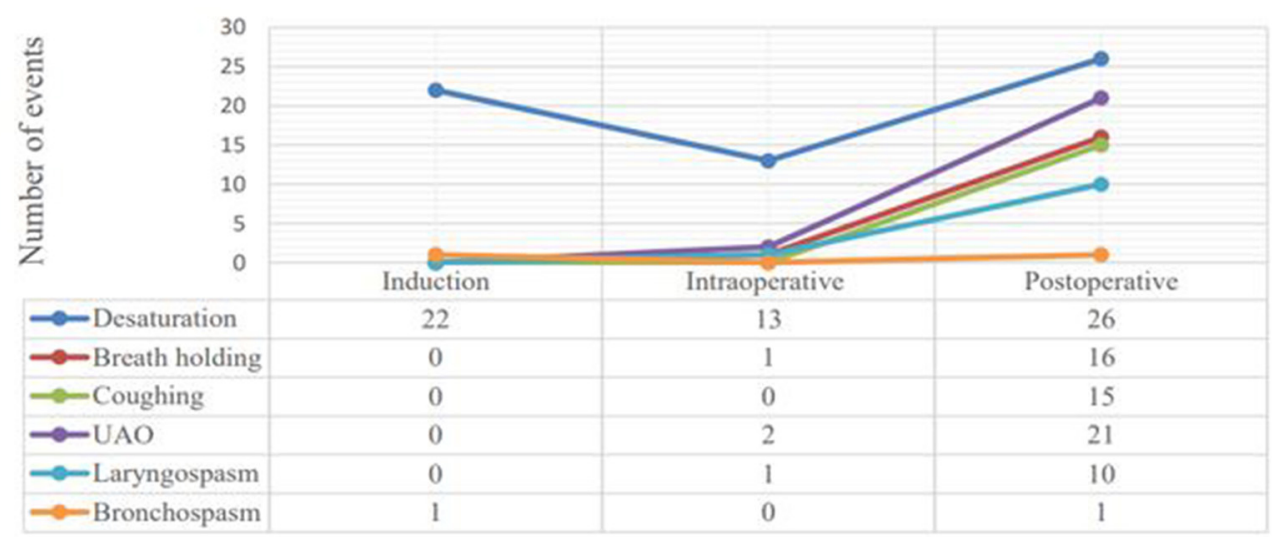

FIGURE 1 | Line graphs showing the frequency of respiratory adverse events among distinct phases of the perioperative period in pediatric surgical patients at UoGCSH and TGSH, Northwest Ethiopia; March 1-May 30, 2020 ( $N=20)$. 
TABLE 3 | Pearson Chi-squared and Fisher-exact tests; factors associated with perioperative respiratory adverse events among pediatric surgical patients underwent surgery under general anesthesia at UoGCSH and TGSH, Northwest Ethiopia; March 1-May 30, 2020 ( N = 210).

\begin{tabular}{|c|c|c|c|c|c|c|c|}
\hline Variables & $\begin{array}{c}\text { Frequency } \\
\text { n (\%) }\end{array}$ & $\begin{array}{c}\text { Desaturation } \\
n(\%)\end{array}$ & $\begin{array}{l}\text { Breath } \\
\text { holding } \\
\text { n (\%) }\end{array}$ & $\begin{array}{c}\text { Coughing } \\
n(\%)\end{array}$ & $\begin{array}{c}\text { Airway } \\
\text { obstruction } \\
n(\%)\end{array}$ & $\begin{array}{l}\text { Laryngospasm } \\
\qquad n(\%)\end{array}$ & $\begin{array}{c}\text { Bronchospasm } \\
n(\%)\end{array}$ \\
\hline \multicolumn{8}{|l|}{ Age } \\
\hline$\leq 1$ year & $52(24.8)$ & $22(44.0)^{a}$ & $8(50.0)$ & $8(53.3)^{b}$ & 5 (23.8) & $5(41.7)$ & $1(1.9)$ \\
\hline > 1year & 158 (75.2) & 28 (56.0) & $8(50.0)$ & 7 (46.7) & 16 (76.2) & 7 (58.3) & $1(0.6)$ \\
\hline \multicolumn{8}{|l|}{ ASA } \\
\hline$\geq 3$ & $21(10)$ & $14(28.0)^{a}$ & $2(12.5)$ & 5 (33.3) & 8 (38.1) & 2 (16.7) & 0 \\
\hline$\leq 2$ & $189(90)$ & 36 (72.0) & $14(87.5)$ & $10(66.7)$ & $13(61.9)$ & 10 (83.3) & $2(1.1)$ \\
\hline \multicolumn{8}{|l|}{ URTI } \\
\hline Yes & $23(11)$ & $17(34.0)^{a}$ & 4 (25.0) & $6(40)^{b}$ & $6(28.5)^{b}$ & $5(41.7)^{b}$ & 0 \\
\hline No & 187 (89) & 33 (66.0) & $12(75.0)$ & $9(60)$ & 15 (71.5) & 7 (58.3) & $2(1.1)$ \\
\hline \multicolumn{8}{|l|}{ Attempts } \\
\hline$\geq 3$ & $9(4.30)$ & $7(14.0)^{b}$ & 2 (12.5) & $1(6.7)$ & 0 & $3(25)^{b}$ & $1(50)$ \\
\hline$\leq 2$ & 201 (95.7) & 38 (86.0) & $14(87.5)$ & 14 (93.3) & $21(100)$ & $9(75)$ & $1(50)$ \\
\hline \multicolumn{8}{|l|}{ Secretion } \\
\hline Yes & $26(12.4)$ & $15(30.0)^{a}$ & $5(31.2)^{b}$ & $8(53.3)^{b}$ & $9(42.8)^{b}$ & $5(41.7)^{b}$ & 0 \\
\hline No & 184 (87.6) & 35 (70.0) & $11(68.8)$ & 7 (46.7) & 12 (57.2) & 7 (58.3) & $2(1.1)$ \\
\hline \multicolumn{8}{|l|}{ Procedures } \\
\hline Airway & 25 (11.9) & $10(20)^{a}$ & 3 (18.75) & 4 (26.6) & 7 (33.3) & 4 (33.3) & 0 \\
\hline Non-airway & $185(88.1)$ & $40(80)$ & $13(81.2)$ & $11(73.4)$ & $14(66.7)$ & $8(66.7)$ & $2(1.1)$ \\
\hline \multicolumn{8}{|c|}{ Family history of Asthma } \\
\hline Yes & $4(1.9)$ & $4(8.0)$ & 0 & 0 & $1(4.7)$ & 0 & $2(50.0)^{b}$ \\
\hline No & $206(98.1)$ & $46(92.0)$ & $16(100)$ & $15(100)$ & 20 (95.3) & $12(100)$ & 0 \\
\hline
\end{tabular}

a Significant in Pearson Chi-square test.

${ }^{b}$ Significant in Fisher-exact test.

years. Most of the patients 189 (90\%) were classified under ASA 1 and 2 while the rest were ASA 3 and above. The $23(11 \%)$ patients had URTIs. Eighty-nine (42.4\%) patients had low hemoglobin levels $(<11 \mathrm{~g} / \mathrm{dl})$ preoperative. The mean duration of surgery was $82 \pm 41.5 \mathrm{~min}$ (Table 2).

Out of 210 pediatric patients, 55 (26.2\%, CI: 20.5-30.9\%) had developed PRAEs. We have observed 129 episodes of PRAEs and desaturation was the commonest adverse event which occurred 61 (47.3\%) times; followed by partial upper airway obstruction $21(16.3 \%)$, breath holding 17 (13.2\%), persistent coughing 15 (11.6\%), laryngospasm 11 (8.5\%) and bronchospasm 2 (1.6\%). Of 129 episodes of PRAEs, 89 (69.0\%) occurred in the postoperative period while 23 (17.8) were occurred during induction of anesthesia, and 17 (13.2\%) during the maintenance phase (Figure 1).

Among four pediatric surgical patients who had family history of asthma, bronchospasm occurred in the two of them. One was during induction of anesthesia and the other was after extubation. Fisher-exact test has showed the significant association between family history of asthma and per ioperative bronchospasm. However, none of the children had self-history of asthma. The relations of independent variables with outcome variables in Pearson's Chi-squared and Fisher-exact tests are presented (Table 3). Regarding severity of PRAEs, $10(4.8 \%)$ patients had serious desaturation $\left(\mathrm{SpO}_{2}<80 \%\right)$ and $1(0.5 \%)$ patient had continuous coughing, $3(1.4 \%)$ patients had complete airway obstruction which required muscle relaxant, and 9 (4.3\%) patients had laryngospasm which was effectively managed by the applications of simple airway maneuvers and positive airway pressure (Table 4).

In bivariate binary logistic regression analysis, comorbidity, emergency surgery, multiple attempts of tracheal intubation ( $\geq 3$ attempts), light anesthesia, perioperative opioid use and duration of surgery $\geq 60 \mathrm{~min}$ were found associated with PRAEs. The final multivariate binary logistic regression analysis demonstrated that age $<1$ year, URTIs (recent or active), secretions in the upper airways, ASA $\geq 3$ and airway related surgery were associated with PRAEs.

Among pediatric surgical patients, those who had URTIs were more than seven times likely to develop PRAEs (AOR: 7.6, CI: $1.9-30.2$, p: 0.004). The likelihood of PRAEs to occur in infants was 3.6 times than older pediatric surgical patients (AOR: 3.6, CI: $1.3-10.0$, p: 0.012). Interestingly, repeated attempts of tracheal intubation were noticed among infants (66.6 vs. $33.3 \%$, p: 0.008). ASA physical status of three and above increases the occurrence of PRAEs by more than 5 folds (AOR: 5.2, CI: 1.9-22.9, p: 0.029). Pediatric surgical patients who underwent airway related procedures had developed PRAEs more frequently compared to their counterparts (AOR: 6.0, CI: 1.5-24.1, p: 0.012). Having moderate to copious oropharyngeal secretions was found associated with the occurrence of PRAEs (AOR: 4.8, CI: 1.4$15.9, p: 0.011)$. The results of this study claimed that prematurity, 
TABLE 4 | Severity of perioperative respiratory adverse events among pediatric surgical patients underwent surgery under general anesthesia at UoGCSH and TGSH, Northwest Ethiopia; March 1-May 30, 2020 ( $N=210)$.

\begin{tabular}{lcccc}
\hline Variables & \multicolumn{4}{c}{ Severity Score $\boldsymbol{n}(\%)$} \\
\cline { 2 - 5 } & $\mathbf{1}$ & $\mathbf{2}$ & $\mathbf{3}$ & $\mathbf{4}$ \\
\hline $\mathrm{SpO}_{2}$ & $160(76.2)$ & $22(10.5)$ & $18(8.6)$ & $10(4.8)$ \\
Coughing $(n)$ & $194(92.4)$ & $2(1)$ & $14(6.7)$ & 0 \\
Breath holding (seconds) & $195(92.9)$ & $9(4.3)$ & $5(2.4)$ & $1(0.5)$ \\
Laryngospasm & $177(84.2)$ & $21(10)$ & $9(4.3)$ & $3(1.4)$ \\
Bronchospasm & $208(99)$ & $1(0.5)$ & $1(0.5)$ & 0 \\
Secretions & $184(87.6)$ & 0 & $15(7.1)$ & $11(5.2)$ \\
\hline
\end{tabular}

premedication, induction agents, types of airway devices and experiences of the anesthetists were not associated with PRAEs (Table 5).

\section{DISCUSSION}

The overall prevalence of PRAEs among pediatric surgical patients who underwent surgery under general anesthesia at UoGCSH and TGCSH was high (26.2\%). This result was congruent with a study done by Mamie et al. in which it was $21 \%$ (1). A systematic review also has revealed that the prevalence of PRAEs was in the ranges of 8-21\% (2). Similarly, Ramgolam et al. concluded that the prevalence of PRAEs was $26-43 \%$ (7). The differences can be explained by the inclusion of only patients who had higher risk of developing PRAEs in the former study.

Prevalence of PRAEs was higher in our study compared to previous study in which it was $15 \%$ (15). The deviations could be due to inclusion of infants in our study as we noticed an increased occurrence of PRAEs in infants compared to older children. In addition, previous multiple studies verified lower prevalence of PRAEs compared to the current study $(2.8,5.7$, and 17.8\%) (2729). Higher prevalence in our study might be due to the inclusion of patients with higher ASA physical status $(\geq 3)$, recovery of pediatrics patients at post-anesthesia care unit that were not staffed with professionals with special pediatric trainings and illequipped recovery area. A retrospective multicenter study done among 25,098 patients showed that the prevalence of PRAEs was $4.6 \%$. The discrepancies might be explained by the incorporation of a large numbers of emergency patients in our study (54.3 vs. $27.4 \%)$ (12). In-addition, differences in the definitions of PRAEs, study design and sample sizes might explain it.

Oxygen desaturation was occurred in 50 (23.8\%) patients which was the commonest PRAE, particularly among patients who had URTIs and airway secretions. This finding was similar with a multicenter study in terms of the overall occurrence. However, it was more frequent intraoperatively compared to emergence (12). In our study, desaturation was common after tracheal extubation. Anesthetic agents are known for diminishing respiratory drive that can results in hypoxemia in the postoperative period (30). Furthermore, almost all types of PRAEs can lead to desaturation.
Persistent coughing and upper airway obstruction were occurred in $15(7.1 \%)$ and $21(10 \%)$ patients respectively. In a previous study, the prevalence of upper airway obstruction was 3.6-9\% (2). Budic and Simic have reported that persistent coughing was occurred only in three out of 682 patients $(0.004 \%)$. The differences in definitions of persistent coughing might cause the inconsistencies. In the current study, persistent coughing was defined as coughing that sustained for $5 \mathrm{~s}$; however, others have defined it as coughing that sustained for $5-10 \mathrm{~s}(28,29)$.

Breathe holding was occurred in $16(7.6 \%)$ patients and it was higher compared to a study done by Tait et al. (23). A large numbers of infant patients [52 (24.8\%)] were included in our study. Younger children have a tidal volume that occurs at the same volume as a closing volume; therefore, the terminal bronchioles close easily causing apnea and desaturation (30). Furthermore, neuromuscular blocking agents were used extensively in 120 (57.1\%) patients. This might contribute for higher incidence of breath holding among our patients (31). In our study areas, there was no any qualitative monitoring of residual neuromuscular blockade.

The prevalence of laryngospasm was $12(5.7 \%)$ and consistent with a systematic review which claimed $0.1-16 \%$. Particularly, it was $4 \%$ in general pediatric population (2). The commonest time of occurrence was extubation. Similarly to previous studies, laryngospasm was associated with presence of airway secretions and URTIs $(22,32)$. Family history of asthma was associated with perioperative bronchospasm. The phenomenon can be explained by bronchial hyper-responsiveness in children born from parents who have asthma (33).

Children that presented with recent or active sign and symptoms of URTIs were found to have increased risk of developing PRAEs (73.9\%). The higher risk of PRAEs during URTIs can be justified by the morphologic damage to the epithelium and mucosa of the respiratory tract after infections and make the airway sensitive to potentially irritant anesthetic gases and secretions that result in activation of irritant receptors and contractions of airway smooth muscles (30). A study has showed that there was increased incidence of PRAEs in patients with an active URTIs than those who had recent URTIs (2-4 weeks before the procedure) (34). The effects of URTIs on the airway could last for several weeks (3). In our study there was no significant difference in the occurrence of PRAEs whether the URTI is recent or active ( 84.6 vs. $60 \%, p$ : 0.34$)$. The occurrence of PRAEs was significantly higher immediately after tracheal extubation than induction and maintenance phases (30).

Infants were more vulnerable to develop PRAEs than older patients $(8,20)$. Desaturation occurs more frequently in infants $(5,8)$. Infants have higher oxygen demand and low oxygen reserves which make them risky to PRAEs such as hypoxia. Breath holding was common in this group of patients due to immature respiratory center. Additionally, we have noticed that multiple attempts of tracheal intubation in infants than older patients (66.7 vs. $33.3 \%, p$ : 0.008$)$. A previous study concluded that multiple intubation attempts were associated with PRAEs (20).

There was higher occurrence of PRAEs among patients with higher ASA physical status $(\geq 3)$ and this is supported by 
TABLE 5 | Bivariate and multivariate binary logistic regression analysis: factors associated with PRAEs in pediatric surgical patients underwent surgery under general anesthesia in UoGCSH and TGSH, Northwest Ethiopia; March 1-May 30, 2020 ( $N=210)$.

\begin{tabular}{|c|c|c|c|c|c|}
\hline \multirow[t]{2}{*}{ Variables } & \multicolumn{2}{|c|}{ PRAEs } & \multicolumn{2}{|c|}{ Odds ratio $(95 \% \mathrm{Cl})$} & \multirow[t]{2}{*}{$p$-values } \\
\hline & Yes $n(\%)$ & No $n(\%)$ & Crude & Adjusted & \\
\hline \multicolumn{6}{|l|}{ Age } \\
\hline$<1$ year & $22(42.3)$ & $30(57.7)$ & $2.8(1.4,5.4)$ & $3.6(1.3,10.0)$ & 0.012 \\
\hline$\geq 1$ year & $33(20.9)$ & $125(79.1)$ & 1 & 1 & \\
\hline \multicolumn{6}{|l|}{ ASA class } \\
\hline$\geq 3$ & $15(71.4)$ & $6(28.6)$ & $9.31(3.4,25.8)$ & $5.2(1.2,22.9)$ & 0.029 \\
\hline$\leq 2$ & $40(21.2)$ & $149(78.8)$ & 1 & 1 & \\
\hline \multicolumn{6}{|c|}{ Urgency of the procedure } \\
\hline Emergency & 39 (34.2) & $75(65.8)$ & $2.6(1.3,5.0)$ & $1.41(0.5,3.7)$ & 0.48 \\
\hline Elective & $16(16.7)$ & 80 (83.3) & 1 & 1 & \\
\hline \multicolumn{6}{|l|}{ URTIs } \\
\hline Yes & $17(73.9)$ & $6(26.1)$ & $11.1(4.1,30.1)$ & $7.5(1.9,30.2)$ & 0.004 \\
\hline No & 38 (20.3) & $149(79.7)$ & 1 & 1 & \\
\hline \multicolumn{6}{|l|}{ Surgical procedures } \\
\hline Airway related & $12(48.0)$ & $13(52.0)$ & $3.0(1.3,7.2)$ & $6.0(1.5,24.1)$ & 0.012 \\
\hline Non-airway related & $43(23.2)$ & $142(76.8)$ & 1 & 1 & \\
\hline \multicolumn{6}{|c|}{$\begin{array}{l}\text { Secretions in the upper } \\
\text { airway }\end{array}$} \\
\hline Moderate to copious & $18(69.2)$ & $8(30.8)$ & $8.9(3.6,22.2)$ & $4.78(1.4,18.8)$ & 0.011 \\
\hline None to minimal & $37(20.1)$ & 147 (79.9) & 1 & 1 & \\
\hline \multicolumn{6}{|l|}{ Light anesthesia } \\
\hline Yes & $10(41.7)$ & $14(58.3)$ & $2.2(0.9,5.4)$ & $2.6(0.7,9.8)$ & 0.14 \\
\hline No & $45(24.2)$ & $141(75.8)$ & 1 & 1 & \\
\hline \multicolumn{6}{|l|}{ Intubation attempts } \\
\hline$\geq 3$ & $7(77.8)$ & $2(22.2)$ & $11(2.2,55.0)$ & $3.9(0.5,28.0)$ & 0.17 \\
\hline$\leq 2$ & $42(24.1)$ & $132(75.9)$ & 1 & 1 & \\
\hline \multicolumn{6}{|c|}{ Duration of surgery (hour) } \\
\hline$\geq 1$ & $39(37.7)$ & $84(68.3)$ & $2(1.1,4.0)$ & $2.0(0.7,5.9)$ & 0.19 \\
\hline$<1$ & $16(18.4)$ & $71(81.6)$ & 1 & 1 & \\
\hline
\end{tabular}

NB: $p$-values are from multivariate binary logistic regression analysis.

previous studies $(4,11)$. In developing countries, anesthetists frequently encounter patients with poorly treated comorbidities which could lead to the occurrence of PRAEs $(4,5,35)$. The majority of the patients were underwent emergency surgery 114 (54\%); therefore, poor preoperative optimization might contribute for higher incidence of PRAEs (35).

The risk of developing PRAEs was increased by 6-folds when a surgical procedure involves the airway. Airway related procedures were associated with frequent desaturation and upper airway obstruction. Our finding was supported by previous multicenter prospective studies $(3,5,36)$. Children who need airway related surgery commonly have chronic airway inflammation and bronchial hypersensitivity that could result in PRAEs. Surgical instrumentation and manipulation of the airway can lead to laryngeal reflex response (2). Moderate to copious airway secretions was found associated with PRAEs, particularly with desaturation and partial upper airway obstruction. Soiling of the airway which necessitate repeated suctioning can potentiate airway hyper-reactivity (23).

A multicenter study done by Habre et al. including 261 hospitals across Europe has concluded that the experience of the team of anesthesia providers was a very important factor that determines the safety and the rate of adverse events in the pediatric anesthesia practices (37). Our study have not showed this association. The discrepancy might be due to smaller sample size and setup differences as only two hospitals included in the current study done in a developing country.

The study was the first for its type in our country and we believe that it can be a foundation for future studies in the field; especially in resource-limited settings. Hypoventilation and residual neuromuscular blockade were not measured due to the lack of the devices in the post-anesthesia care units of the hospitals. Smaller sample size due to COVID-19 pandemic is another limitation of this study.

\section{CONCLUSIONS}

There was high prevalence of perioperative respiratory adverse events among pediatric surgical patients. The postoperative period was the most critical time for the occurrence of PRAEs and desaturation was the commonest adverse event. Age $<1$ year, URTIs (recent or active), secretions in the upper airways, 
ASA $\geq 3$ and airway surgery were significantly associated with adverse events. Clinicians should perform effective risk assessment, optimization and preparation for the management of perioperative respiratory adverse events.

\section{DATA AVAILABILITY STATEMENT}

The raw data supporting the conclusions of this article will be made available by the authors, without undue reservation.

\section{ETHICS STATEMENT}

The studies involving human participants were reviewed and approved by University of Gondar. Written informed consent to

\section{REFERENCES}

1. Mamie C, Habre W, Delhumeau C, Barazzone Argiroffo C, Morabia A. Incidence and risk factors of perioperative respiratory adverse events in children undergoing elective surgery. Pediatric Anesthesia. (2004) 14:21824. doi: 10.1111/j.1460-9592.2004.01169.x

2. Regli A, von-Ungern-Sternberg BS. Diagnosis and management of respiratory adverse events in the operating room. Curr Anesthesiol Rep. (2015) 5:15667. doi: 10.1007/s40140-015-0103-z

3. von-Ungern-Sternberg BS, Davies K, Hegarty M, Erb TO, Habre W. The effect of deep vs. awake extubation on respiratory complications in high-risk children undergoing adenotonsillectomy: a randomised controlled trial. Eur J Anaesthesiol. (2013) 30:529-36. doi: 10.1097/EJA.0b013e32835 df608

4. Lee S, Reddington E, Koutsogiannaki S, Hernandez MR, Odegard KC, DiNardo JA, et al. Incidence and risk factors for perioperative cardiovascular and respiratory adverse events in pediatric patients with congenital heart disease undergoing noncardiac procedures. Anesth Analg. (2018) 127:7249. doi: 10.1213/ANE.0000000000003406

5. Murat I, Constant I, Maud'huy H. Perioperative anaesthetic morbidity in children: a database of 24165 anaesthetics over a 30-month period. Paediatr Anaesth. (2004) 14:158-66. doi: 10.1111/j.1460-9592.2004.01167.x

6. Hackett S, Jones R, Kapila R. Anaesthesia for pneumonectomy. BJA Education. (2019) 19:297-304. doi: 10.1016/j.bjae.2019.04.004

7. Ramgolam A, Hall GL, Zhang G, Hegarty M, von-Ungern-Sternberg BS. Inhalational versus intravenous induction of anesthesia in children with a high risk of perioperative respiratory adverse events; a randomized controlled trial. Anesthesiology. (2018) 128:1065-74. doi: 10.1097/ALN.0000000000002152

8. Drake-Brockman TF, Ramgolam A, Zhang G, Hall GL, von Ungern-Sternberg BS. The effect of endotracheal tubes versus laryngeal mask airways on perioperative respiratory adverse events in infants: a randomised controlled trial. Lancet. (2017) 389:701-8. doi: 10.1016/S0140-6736(16)31719-6

9. Lerman J. Perioperative respiratory complications in children. Lancet. (2010) 376:745-6. doi: 10.1016/S0140-6736(10)61199-3

10. Najafi N, Veyckemans F, Vanhonacker D, Legrand C, Van de Velde A, Vandenplas $\mathrm{Y}$, et al. Incidence and risk factors for adverse events during monitored anaesthesia care for gastrointestinal endoscopy in children: a prospective observational study. Eur J Anaesthesiol. (2019) 36:3909. doi: 10.1097/EJA.0000000000000995

11. Charuluxananan S, Suraseranivongse S, Jantorn P, Sriraj W, Chanchayanon T, Tanudsintum S, et al. Multicentered study of model of anesthesia related adverse events in Thailand by incident report (The Thai Anesthesia Incidents Monitoring Study) results. J Med Assoc Thai. (2008) 91:1011.

12. Bunchungmongkol N, Somboonviboon W, Suraseranivongse $\mathrm{S}$, Vasinanukorn M, Chau- in W, Hintong T. Pediatric anesthesia adverse events: the Thai Anesthesia Incidents Study (THAI Study) database of 25,098 cases. J Med Assoc Thai. (2007) 90:2072. participate in this study was provided by the participants' legal guardian/next of kin.

\section{AUTHOR CONTRIBUTIONS}

DW and YWB have conceptualized the study, objectives, and manuscript preparation. DW has developed the proposal. YWB, WC, HA, and MW have criticized the proposal. All authors had participated in the data and statistical analyses and read and approved the final manuscript.

\section{FUNDING}

This work was supported by University of Gondar and Health Bureau of Amhara National Regional State, Ethiopia.

13. von-Ungern-Sternberg BS, Boda K, Schwab C, Sims C, Johnson C, Habre W. Laryngeal mask airway is associated with an increased incidence of adverse respiratory events in children with recent upper respiratory tract infections. Anesthesiology. (2007) 107:714-9. doi: 10.1097/01.anes.0000286925.25272.b5

14. Mir ghassemi A, Neira V, Ufholz LA, Barrowman N, Mulla J, Bradbury CL, et al. A systematic review and meta-analysis of acute severe complications of pediatric anesthesia. Paediatr Anaesth. (2015) 25:1093-102. doi: 10.1111/pan.1 2751

15. von-Ungern-Sternberg BS, Boda K, Chambers NA, Rebmann C, Johnson C, Sly PD, et al. Risk assessment for respiratory complications in paediatric anaesthesia: a prospective cohort study. Lancet. (2010) 376:773-83. doi: 10.1016/S0140-6736(10)61 193-2

16. Li L, Zhang Z, Yao Z, Wang H, Wang H, An H, et al. The impact of laryngeal mask versus other airways on perioperative respiratory adverse events in children: a systematic review and meta-analysis of randomized controlled trials. IJS. (2019) 64:40-8. doi: 10.1016/j.ijsu.2019.02.020

17. Terry KL, Disabato J, Krajicek M. Snoring, trouble breathing, un-refreshed (STBUR) screening questionnaire to reduce perioperative respiratory adverse events in pediatric surgical patients: a quality improvement project. AANA J. (2015) 83:256-62.

18. Desalu I, Adeyemo W, Akintimoye M, Adepoju A. Airway and respiratory complications in children undergoing cleft lip and palate repair. Ghana Med J. (2010) 44:16-20. doi: 10.4314/gmj.v44i1.68851

19. Mason K, Green S, Piacevoli Q. Adverse event reporting tool to standardize the reporting and tracking of adverse events during procedural sedation: a consensus document from the World SIVA International Sedation Task Force. BJA. (2012) 108:13-20. doi: 10.1093/bja/aer407

20. Mandee S, Jitpakdee T, BNS TB, Aroonpruksakul N. The incidence of perioperative adverse events in neonates and infants undergoing non cardiac surgery with general anesthesia. J Med Assoc Thai. (2017) 100:44.

21. Group PALICC. Pediatric acute respiratory distress syndrome: consensus recommendations from the pediatric acute lung injury consensus conference. Pediatr Crit Care Med. (2015) 16:428. doi: 10.1097/PCC.0000000000000350

22. Birlie Chekol W, Yaregal Melesse D. Incidence and associated factors of laryngospasm among pediatric patients who underwent surgery under general anesthesia, in university of gondar compressive specialized hospital, Northwest Ethiopia, 2019: a cross-sectional study. Anesthesiol Res Pract. (2020) 2020:3706106. doi: 10.1155/2020/3706106

23. Tait AR, Malviya S, Voepel-Lewis T, Munro HM, Siewert M, Pandit UA. Risk factors for perioperative adverse respiratory events in children with upper respiratory tract infections. Anesthesiology. (2001) 95:299-306. doi: 10.1097/00000542-20010800000008

24. Katz SL, Monsour A, Barrowman N, Hoey L, Bromwich M, Momoli F, et al. Predictors of postoperative respiratory complications in children undergoing adinotonsilectomy. J Clin Sleep Med. (2020) 16:41-8. doi: 10.5664/jcsm.8118 
25. Luce V, Harkouk H, Brasher C, Michelet D, Hilly J, Maesani M, et al. Supraglottic airway devices vs tracheal intubation in children: a quantitative meta-analysis of respiratory complications. Paediatr Anaesth. (2014) 24:108898. doi: 10.1111/pan.12495

26. Kim SY, Kim JM, Lee JH, Kang YR, Jeong SH, Koo B-N. Perioperative respiratory adverse events in children with active upper respiratory tract infection who received general anesthesia through an orotracheal tube and inhalation agents. KJA. (2013) 65:136. doi: 10.4097/kjae.2013.65.2.136

27. Subramanyam R, Yeramaneni S, Hossain MM, Anneken AM, Varughese AM. Perioperative respiratory adverse events in pediatric ambulatory anesthesia: development and validation of a risk prediction tool. Anesth Analg. (2016) 122:1578-85. doi: 10.1213/ANE.0000000000001216

28. Gharaei B, Aghamohammadi H, Jafari A, Razavi S, Kamranmanesh M, Kermany ASP. Use of laryngeal mask airway in children with upper respiratory tract infection, compared with face mask: randomized single blind clinical trial. Acta Anaesthesiol Taiwan. (2011) 49:13640. doi: 10.1016/j.aat.2011.11.008

29. de Carvalho ALR, Vital RB, de Lira CCS, Magro IB, Sato PTS, Lima LHN, et al. Laryngeal mask airway versus other airway devices for anesthesia in children with an upper respiratory tract infection: a systematic review and meta-analysis of respiratory complications. Anesth Analg. (2018) 127:94150. doi: 10.1213/ANE.0000000000003674

30. Budić I, Simić D. Risk factors for respiratory adverse events during general anesthesia in children. Emergency. (2004) 11:118-22.

31. Murphy GS, Szokol JW, Marymont JH, Greenberg SB, Avram MJ, Vender JS. Residual neuromuscular blockade and critical respiratory events in the post-anesthesia care unit. Anesth Analg. (2008) 107:1307. doi: 10.1213/ane.0b013e31816d1268

32. Haile M, Legesse S, Miressa S, Desalegn N. Magnitude and associated risk factors of perioperative pediatrics laryngospasm under general anesthesia. InternMed. (2015) 5:2.

33. Jackson O, Basta M, Sonnad S, Stricker P, LaRossa D, Fiadjoe J. Perioperative risk factors for adverse airway events in patients undergoing cleft palate repair. Cleft Palate Craniofac J. (2013) 50:330-6. doi: 10.1597/12-134
34. Li C, Wang D, Cheng T, Zheng X. Effects of recent upper respiratory-tract infections on incidence of the perioperative respiratory adverse events in children: a prospective cohort study. Journal of Peking University Health sciences. (2017) 49:814-8.

35. Amucheazi AO, Ajuzieogu OV. Critical incidents during anesthesia in a developing country: A retrospective audit. Anesth Essays Res. (2010) 4:648. doi: $10.4103 / 0259-1162.73508$

36. Virag K, Sabourdin N, Thomas M, Veyckemans F, Habre W. Epidemiology and incidence of severe respiratory critical events in ear, nose and throat surgery in children in Europe: a prospective multi-center observational study. Eur J Anaesthesiol. (2019) 36:185-93. doi: 10.1097/EJA.0000000000000951

37. Hebre W, Disma N, Virag K, Beck K, Hansen TG, Johr M, et al. Incidence of sever critical events in paediatric anaesthesia (APRICOT): a prospective multicentre observational study in 261 hospitals in Europe: Lancet. Respir Med. (2017) 5:412-25.

Conflict of Interest: The authors declare that the research was conducted in the absence of any commercial or financial relationships that could be construed as a potential conflict of interest.

Publisher's Note: All claims expressed in this article are solely those of the authors and do not necessarily represent those of their affiliated organizations, or those of the publisher, the editors and the reviewers. Any product that may be evaluated in this article, or claim that may be made by its manufacturer, is not guaranteed or endorsed by the publisher.

Copyright (c) 2022 Wudineh, Berhe, Chekol, Adane and Workie. This is an openaccess article distributed under the terms of the Creative Commons Attribution License (CC BY). The use, distribution or reproduction in other forums is permitted, provided the original author(s) and the copyright owner(s) are credited and that the original publication in this journal is cited, in accordance with accepted academic practice. No use, distribution or reproduction is permitted which does not comply with these terms. 